\title{
REVIEWS
}

\section{The Pathogenesis and Diagnosis of Thromboangiitis obliterans: Is It Still a Mystery?}

${ }^{1}$ Department of Angiology, Hypertension and Diabetology, Wroclaw Medical University, Poland

2 Department and Clinic of Ophthalmology, Wroclaw Medical University, Poland

${ }^{3}$ Department of Vascular, General and Transplantation Surgery, Wroclaw Medical University, Poland

A - research concept and design; $\mathbf{B}$ - collection and/or assembly of data; $\mathbf{C}$ - data analysis and interpretation;

$\mathbf{D}$ - writing the article; $\mathbf{E}$ - critical revision of the article; $\mathbf{F}$ - final approval of article

\begin{abstract}
Thromboangiitis obliterans (TAO) is a rare disease of unknown etiology that results in the occlusion of limb arteries located distally to the elbow and knee. Despite the fact that more than one hundred years have passed since its first description, knowledge on the pathogenesis of TAO and precipitating factors is still limited. Due to a lack of decisive noninvasive diagnostic methods and geographical differences in the prevalence of this condition, data on TAO epidemiology also remains sparse. This review presents important evidence on the pathogenesis and the course of the condition, as well as diagnostic modalities, with a focus on differential diagnosis. Theories on the pathogenesis of TAO include the theory of an infectious disease, coagulation disorders and injury to vascular endothelium resulting in activation of the inflammatory response. Differential diagnosis should exclude thoracic outlet syndrome, blue toe syndrome, infectious endocarditis, popliteal entrapment syndrome, Takayasu disease, primary and secondary systemic vasculitis, antiphospholipid syndrome, infection with the anaerobic Clostridium sp. bacilli and some less common conditions (Adv Clin Exp Med 2015, 24, 6, 1085-1097).
\end{abstract}

Key words: differential diagnosis, thromboangiitis obliterans, Buerger's disease, angiology.

The first report of a new disease that several years later would be named thromboangiitis obliterans (TAO) was made by a German pathologist Carl Friedländer in 1876; it was subsequently also reported by Viennese physician Felix von Winiwarter in 1879 [1]. Von Winiwarter pointed out characteristic features distinguishing this condition from atherosclerosis, specifically hypertrophy of the tunica intima, thrombosis and fibrosis of the vascular wall. The author believed that this disease resulted from excessive overgrowth of the tunica intima, and he therefore referred to it as endarteritis obliterans. However, the first report describing TAO was published by another Austrian, pathologist Leo Buerger, as part of a histological examination of eleven amputated limbs. His paper, entitled "Thromboangiitis obliterans: a study of the vascular lesions leading to presenile spontaneous gangrene", was published in 1908. In it he wrote: "There is an interesting group of cases characterized by typical symptoms which the Germans have described under the name »Spontan-gangrän «. [...] The disease occurs frequently, although not exclusively, among the Polish and Russian Jews, and it is in the dispensaries and hospitals of New York City that we find a good opportunity for studying it in its two phases, namely in the period which precedes and in that which follows the onset of the gangrene" [2].

More than 120 years have passed since this description of TAO was published. During this period, have we gotten closer to understanding the reasons behind this condition or arrived at more appropriate diagnostic methods? It seems that a clearly affirmative answer cannot be given. 


\section{Epidemiological Problems}

The actual prevalence of TAO has not been established precisely due to at least two reasons: 1 . geographical differences in the prevalence of this condition, and 2. the lack of non-invasive diagnostic methods enabling differentiation between TAO and obliterative atherosclerosis in individuals with a mild degree of ischemia (e.g., stage IIA according to Fontaine). India, Korea and Japan have the highest prevalence of TAO (according to various authors up to $50 \%$ of patients with peripheral artery disease are affected), while the corresponding numbers for Western Europe are in the range of $0.50-5.6 \%$ [3]. Contrary to frequently repeated data in the literature (including data published by the authors of this review) regarding a particularly high prevalence of TAO among Ashkenazi Jews, the condition does not affect this group more frequently than the population of Western Europe, not exceeding $5 \%$ of individuals with peripheral artery disease, as was recently highlighted by Prof. Raphael Adar [4]. Furthermore, little data was gathered regarding the general population. In the 1970s and 1980s, the prevalence of TAO in North America was estimated at $8-11.6 / 100000$; it is known that this figure has decreased considerably in the last 30 years due to unexplained reasons [5].

A lower frequency of TAO diagnoses in the 1960s and 1970s (which can be called a "pseudodecrease in incidence") can be explained by the implementation of novel diagnostic methods. Józef Kaniak, a scientist experienced with TAO, wrote in the early 1980s: "Between 1928 and 1956, when the arteriographic examination was not performed so commonly, the diagnosis of Buerger's disease was overused and this condition was ascribed to most cases of peripheral artery disease. Implementation of novel diagnostic methods and, in particular, angiographic examination, has revealed typical atherosclerotic lesions in many cases that were originally classified as Buerger's disease" [6].

In contrast, the decrease in the incidence of TAO observed in the 1980s, although widely noted, is not so easy to explain. According to Wysokiński et al. [7], in the period from 1971 to $1980,18 \%$ of all patients with peripheral artery disease treated

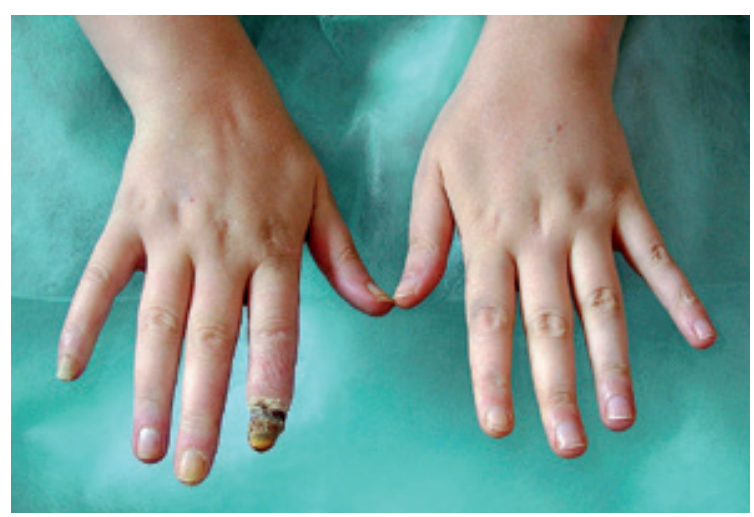

Fig. 1. A 40-year-old female patient with a diagnosis of $\mathrm{TAO}$ and involvement of the hands and feet. Necrosis of the distal part of the forefinger; ischemia of all fingers of both hands (authors' own image)

at their facility in Wroclaw, Poland, were TAO patients, while in 1990 this percentage amounted to only $4 \%$. In those authors' opinion, the decrease was most evident in 1980-1986.

The decrease in the general incidence of TAO occurred simultaneously with a relative increase in the prevalence of this condition among women (Fig. 1). According to data collected by the Mayo Clinic, women comprised $15.8 \%$ of the newly diagnosed cases of TAO in the period from 1976 to 1980, while in 1996-1999 this percentage increased to $36.4 \%$ [8]. In a study by Sasaki et al. conducted in the Japanese population in the late 1990s [9], the percentage of women affected with TAO amounted to $9.3 \%$ and was several times higher than in the 1980s.

Table 1 summarizes the number of patients who were hospitalized due to TAO at the Clinic of Angiology, Arterial Hypertension and Diabetology at the Wrocław Medical University between 2002 and 2010. As shown, only small fluctuations in the number of patients have occurred during recent years, with the rate of hospitalization amounting to approximately 20-30 individuals per year. After a transient increase in the percentage of women hospitalized due to TAO (up to $27 \%$ in 2003), no female patient with this condition has been hospitalized during the last two years. It is, however, difficult to assess whether this is an established tendency.

Table 1. Number of hospitalizations due to TAO at the Clinic of Angiology, Arterial Hypertension and Diabetology at Wroclaw Medical University (Poland) in 2002-2010

\begin{tabular}{|l|l|l|l|l|l|l|l|l|l|}
\hline Year & 2002 & 2003 & 2004 & 2005 & 2006 & 2007 & 2008 & 2009 & 2010 \\
\hline No. of hospitalizations & 33 & 31 & 35 & 33 & 25 & 22 & 18 & 25 & 32 \\
\hline No. of patients & 23 & 18 & 26 & 18 & 17 & 13 & 14 & 12 & 12 \\
\hline Percentage of female patients (\%) & 21 & 27 & 15 & 5 & 6 & 15 & 7 & 0 & 0 \\
\hline
\end{tabular}




\section{Is TAO an Infectious Disease?}

In one of his later papers, Leo Buerger clearly suggested that TAO is an infectious condition, although he was unable to identify the microorganism responsible [10]. Numerous other authors have called the existence of this etiological factor into question, suggesting that Buerger was wrong. However, after 100 years of scientific research there is some evidence that supports the association between $\mathrm{TAO}$ and infection.

One of the important characteristics that distinguish individuals with TAO from other angiological patients is a higher prevalence of periodontal disease, resulting from a lack of proper hygienic habits and tobacco smoking. For instance, in a study by Chen et al. [11] based on objective methods of assessing periodontal status, significant abnormalities were markedly more frequent in individuals with TAO than in smokers free from this condition ( $89.5 \%$ vs. $28 \%$ ), and the presence of TAO was associated with a high odds ratio of having periodontitis (OR $=7.71$; 95\% CI: 1.04-57.24). Some unique characteristics of the gingival structure, namely rich lymphatic vasculature with large fenestrations present between endothelial cells, enable the penetration of various substances and microorganisms into the lymphatic vessels and thence to the regional lymph nodes [12]. This explains the rapid development of bacteremia (within several minutes) following tooth extraction, or even after the relatively less invasive removal of dental plaque. Under pathological conditions, the contact surface between periodontal pockets and microorganisms can be as large as a fist, enabling the penetration of more than 300 anaerobic bacterial species into systemic circulation [13].

Chen et al. [14] revealed that TAO patients had higher titers of IgG antibodies against Treponema denticola, Porphyromonas gingivalis, and Actinobacillus actinomycetemcomitans as compared to the controls, and Iwai et al. [15] confirmed the presence of bacterial DNA (absent in healthy individuals) in 13 out of 14 specimens of involved arterial walls obtained from TAO patients. Aside from the immune response to the presence of bacterial antigens in the arterial wall, there is also a possibility that bacteria can induce the synthesis of autoantibodies in the mechanism of antigen mimicry. Chen et al. [16] analyzed the homology of amino acid sequences in $P$. gingivalis and T. denticola and that of $\beta_{2}$-glycoprotein I ( $\beta_{2}$-GPI). They concluded that TAO is associated with a higher prevalence of antibodies against $\beta_{2}$-GPI, along with greater severity of periodontal disease and higher antibody titers against the antigens of these bacteria. This finding can explain previous literature reports (see below) of a higher prevalence of antiphospholipid antibodies in this group of patients.

The hypothesis of the pathogenic influence of bacteria forming physiological oral microflora in individuals with TAO is further supported by findings from Kubota et al. [17]. Four weeks after the intravenous administration of $P$. gingivalis to rats, thrombosis was observed in $83.3 \%$ of popliteal artery specimens. A higher predisposition to the aforementioned autoimmune reaction, observed in some populations, may result from the influence of genetic factors. For instance, Chen et al. [18] observed that TAO patients are characterized by a higher prevalence of the TT allele of the CD14 monocyte receptor, which is responsible for binding bacterial lipopolysaccharide.

\section{Coagulation Disorders in TAO}

Many studies have documented an association between TAO and the presence of coagulation system abnormalities. The first group of those studies pertained to the presence of antiphospholipid antibodies in TAO patients. Masłowski et al. [19] observed that individuals with TAO are characterized by a markedly higher prevalence of anti-cardiolipin (aCL) antibodies (36\%) as compared to patients with obliterative atherosclerosis $(8 \%)$ or the controls (2\%). In those authors' opinion, higher titers of $\mathrm{aCL}$ are associated with a higher risk of major limb amputation (i.e., above the knee). Also, a previously mentioned study by Chen et al. [16] documented a higher prevalence of antibodies against $\beta_{2}$-GPI in TAO patients. However, it has not been established thus far whether the presence of antiphospholipid antibodies is a secondary phenomenon, similar to many infectious diseases (such as HBV, HCV, HIV and CMV) [20] or autoimmune conditions (e.g. systemic lupus erythematosus). A literature review published by de Godoy et al. [21] suggests that diseases of the coagulation system and TAO constitute independent entities, and that the presence of aCL in TAO can only be associated with a more severe manifestation of TAO.

Another direction of research pertains to changes in the components of the coagulation and fibrinolysis systems. Undas et al. [22] analyzed 20 TAO patients during a period of remission and revealed unfavorable changes in fibrin clots (reduced permeability, more rapid formation, and decreased susceptibility to lysis). Furthermore, they observed higher concentrations of D dimer, tPA, PAI-1 and fibrinopeptide A. In those authors' 
opinion, these changes may result from the activation of the inflammatory response in the course of TAO. Also, Zheng et al. [23] pointed to a higher concentration of factor VIII antigen, faster adhesion of blood platelets and increased blood viscosity in the course of TAO.

Finally, the third direction of research refers to the identification of congenital genetic polymorphisms that can favor thrombosis. At least two contradictory reports have been published. Avcu et al. [24] stated that nearly all the patients enrolled in their study carried the G20210A polymorphism of the prothrombin gene (in addition to this polymorphism, the prevalence of factor $\mathrm{V}$ Leiden and the polymorphism of the factor $\mathrm{V}$ gene were analyzed). In contrast, no statistically significant differences were documented in a study by Brodmann et al. [25], although the polymorphisms of prothrombin and factor XIII genes were more frequently detected in the TAO group. It is worth adding that in the study by Brodmann et al., deficiencies of anti-thrombin, $\mathrm{C}$ and $\mathrm{S}$ protein, anticardiolipin antibodies and lupus anticoagulant, as well as G20210A polymorphism of the prothrombin gene and Val34Leu polymorphism of the factor XIII gene were considered [25].

Few studies have examined the role of the kinin system in the pathogenesis of TAO. Kinins represent the acute phase mediators and are responsible for vascular dilatation, edema formation and activation of nociceptors; furthermore, they integrate the inflammatory response due to the association with the cytokine and coagulation networks, prostaglandins and nitric oxide. Dellalibera-Joviliano et al. [26] analyzed the kinin system in TAO patients and noted that in addition to an increase in the concentration of low- and highmolecular-weight kininogen, a rise in the activity of kalikrein and kininase II was also observed. Interestingly, those concentrations were higher in current smokers with TAO, suggesting the possibility of a direct association between TAO and smoking. Incidentally, while those authors suggest that their report is the first to describe the role of the kinin system in TAO, Kaniak et al. [27] had depicted similar disorders as early as 1972 .

\section{Injury to the Vascular Endothelium and Activation of the Inflammatory Response}

The functioning of the vascular endothelium can be assessed by means of both imaging studies and laboratory tests. Ultrasonography is a method used to assess the response of the brachial artery to post-ischemic reactive hyperemia (flow-mediated dilatation, or FMD). Idei et al. [28] revealed that patients with TAO have lower FMD values as compared to the controls, although they do not differ significantly from individuals with obliterative atherosclerosis in terms of this parameter. Importantly, the response of the brachial artery wall to nitroglycerine administration remained unchanged, suggesting that dilatation dysfunction results predominantly from endothelial injury. In contrast, Azizi et al. [29] did not observe altered responsiveness of the brachial artery to ischemia, although they documented higher rigidity of the aorta in TAO patients.

A markedly higher number of studies address the morphological and biochemical markers of endothelial injury and dysfunction. Halacheva et al. [30] used histochemical methods and electron microscopy to determine that TAO is associated with elevated expression of both selectin $\mathrm{E}$ (responsible for the initial stage of leukocyte adhesion to endothelial cells and not detected under physiological conditions) and ICAM-1 and VCAM-1 integrins (providing strong adhesion of leukocytes to the endothelial surface), along with the morphological features of endothelial activation. In another study [31], the expression of VCAM-1 was revealed in the region of tunica inti$m a$ (patent vessels) and vasa vasorum (obliterated vessels). This probably leads to an increase in the concentration of circulating adhesion molecules, as observed by Czarnacki et al. [32] with regard to selectins $\mathrm{P}, \mathrm{L}$ and $\mathrm{E}$.

Only a few authors have analyzed the concentrations of cytokines in the course of TAO. Slavov et al. [33] revealed that TAO patients are characterized by an elevated serum concentration of interleukin 6 (IL-6), along with enhanced synthesis of IL- 6 and IL- 12 by peripheral blood mononuclear cells and reduced expression of IL-10. Czarnacki et al. [32] also observed elevated concentrations of endothelin 1, but only in TAO patients with active ischemic ulceration.

Possible relationships between tobacco use and TAO include an allergic-hyperergic reaction to antigens in cigarette smoke, the presence of antielastin antibodies, decreased activity of proteinase inhibitors of and a genetic propensity (certain HLA antigens) [34].

\section{Clinical Signs}

One of the largest studies of TAO patients $(\mathrm{n}=850)$ was presented by Sasaki et al. [9] from Japan. At diagnosis, $8 \%$ of the patients were 
qualified as Fontaine's stage I and $29.6 \%$ to stage II; $23.9 \%$ had resting pain and $38.1 \%$ showed trophic ischemic lesions. Involvement of the upper limbs and migrating phlebitis were observed in $25 \%$ and $16 \%$ of the cases, respectively (Fig. 2). Ates et al. [35] reported different characteristics of the disease in a study of a Turkish population ( $\mathrm{n}=344)$. The most frequent manifestations in this group included cooling of the affected limb (90.6\%), changes in skin coloration $(84.3 \%)$ and ischemic ulceration $(53.1 \%)$, followed by intermittent claudication (48.2\%), and resting pain (46.5\%); simultaneous involvement of upper and lower limbs (4.6\%) or isolated involvement of upper limbs (2\%) were rarely reported. An analysis of TAO patients treated at the present authors' center between 1970 and $1995(\mathrm{n}=377)$ identified intermittent claudication (44\%) and paresthesia (15\%) as the most frequent symptoms, followed by resting pain (9\%) and ischemic ulceration (7\%); migrating superficial phlebitis and Raynaud's syndrome occurred in $23 \%$ and $2 \%$ of the patients, respectively [7].

However, these data refer to previous years and seem not to hold true for currently hospitalized patients. At present, most cases of TAO diagnosed in individuals with resting pain or ischemic ulceration represent higher stages of the disease. In the current authors' opinion, the potential reasons for this situation include: 1 . the development of ambulatory care for patients with peripheral artery disease and probable inclusion of TAO patients in the "preterm atherosclerosis" group; 2. limiting angiographic examination (or CT angiography) to cases of critical ischemia, which results in a lack of clear and irrefutable evidence needed for a diagnosis of TAO; 3 . the increasing popularity of ultrasonographic examination, during which the features of TAO are sometimes difficult to observe; 4 . caution in diagnosing this condition. However, since the therapeutic recommendations for the early stages of both TAO and "premature atherosclerosis" are quite similar (quitting

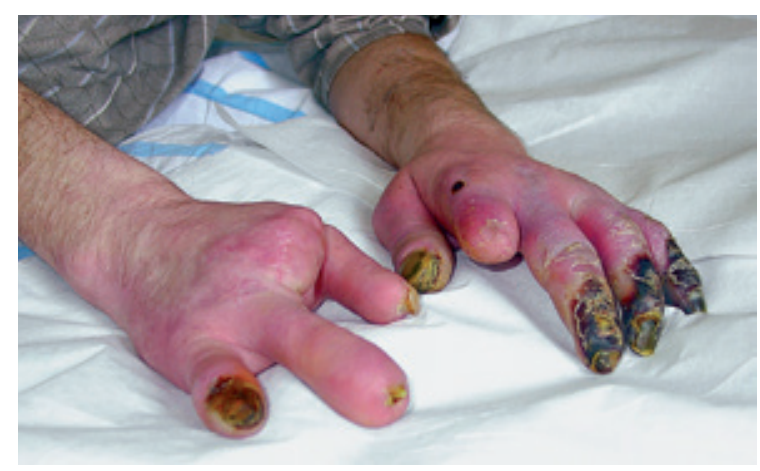

Fig. 2. A repeat exacerbation of TAO in a 40-year-old male patient (authors' own image) smoking, antiplatelet agents, walking exercise) there are no perceived detrimental consequences for TAO patients.

TAO is rarely associated with the involvement of other vascular areas, e.g. celiac arteries, large vessels, or coronary arteries; in such cases the diagnosis is usually established post factum, based on the results of imaging studies.

\section{Diagnostic Criteria}

None of the diagnostic criteria for TAO have been accepted by the international community, although Shionoya's criteria [36], Papa's scoring system [37] and Olin's criteria [3] are frequently referred to in the literature. Common features of all these systems include detecting the disease at 40 to 50 years of age, tobacco smoking and the presence of certain clinical and angiographic characteristic, along with the exclusion of diabetes and autoimmune disorders. However, the clinical manifestations of TAO reported in the last several years suggest that a change in attitude towards this condition is needed. Many patients, particularly those with a history of ischemia-related amputation, show low levels of physical activity and develop obesity and carbohydrate metabolism disorders. Moreover, some patients show signs of a generalized atherosclerotic process co-existing with the features of TAO [38], pointing to the usefulness of the diagnostic criteria published by the Japanese Ministry of Health [9], rarely referred to in either Polish or international literature. Although characterized by a "more liberal" attitude towards diabetes and tobacco smoking, these guidelines precisely define the number of inclusion and exclusion criteria needed to diagnose TAO. Furthermore, the system requires an angiography (Table 2).

Corkscrew collaterals constitute such a specific characteristic of the disease that their shape serves as a criterion in the classification of clinical manifestations. Fujii et al. [39] identified four types of collaterals in TAO patients, differentiated by their helical sign; these collaterals are observed in $64 \%$ of the cases. Type I is characterized by a large helical sign and "tree-root" appearance, while type IV represents a tiny helical sign. In those authors' opinion, types III and IV are a negative prognostic factor because they are associated with a high risk of ulceration: the presence of type III collaterals was associated with 4.64 OR of ulceration (95\% CI: 1.63-48.52), and type IV with 11.33 OR (95\% CI: 1.22-105.56). It is probable that the role of ultrasonography in the diagnosis and monitoring of TAO patients will increase in the future (Fig. 3). 
Table 2. TAO diagnostic criteria published by the Japanese Ministry of Health [9]

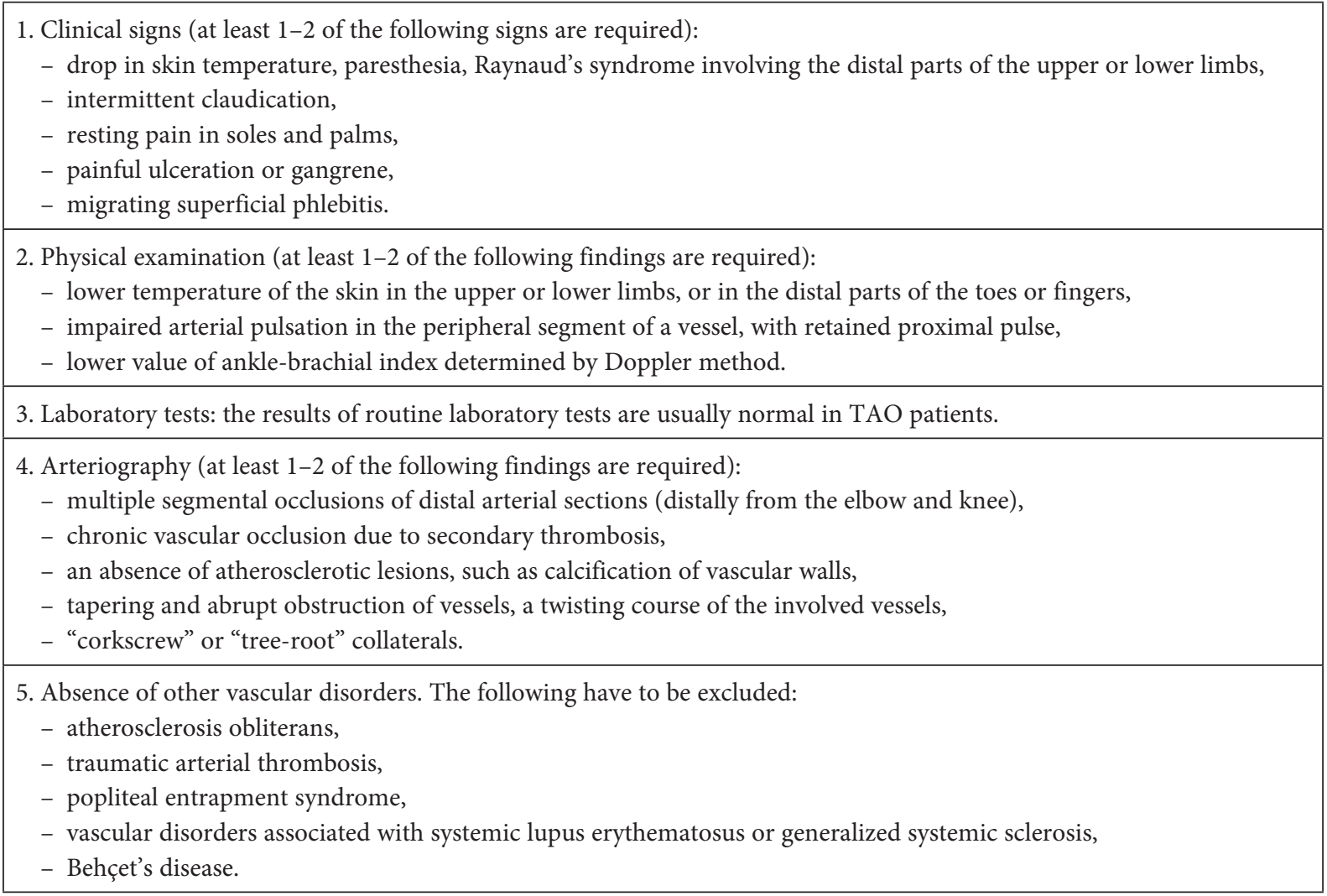

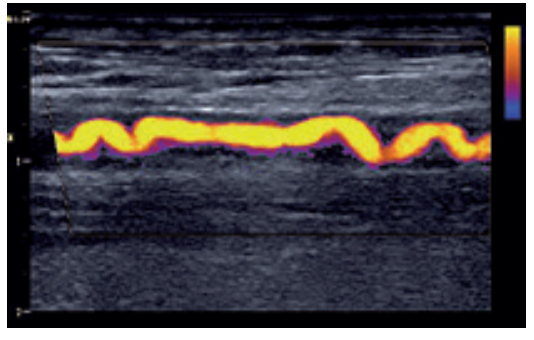

Fig. 3. A characteristic corkscrew-shaped collateral vessel in ultrasonographic examination in a 39 -year-old patient with TAO. The occluded tibial posterior artery can be observed in the background (behind the tiny twisted collateral vessel) (authors' own image)

\section{Differential Diagnosis}

From a practical point of view, in addition to obliterative atherosclerosis, the following important (but unfortunately, rarely included) conditions should also be considered in differential diagnosis.

\section{Thoracic Outlet Syndrome}

Thoracic outlet syndrome (TOS) is associated with considerable diagnostic difficulties. It results from neurovascular disorders within the upper limbs associated with the compression of a neurovascular bundle in the upper thoracic outlet. TOS can be classified as congenital (anatomical malformations, e.g. a cervical rib) or acquired (most commonly post-traumatic). Usually, the neurovascular bundle is compressed at a site of anatomical narrowing, such as the scalene fissure, the costocervical or coracothoracic space. In most cases (90-95\%), it is manifested by neurological symptoms, with vascular involvement observed in $5-10 \%$ of the cases. Numbness and pain in the hands are among the reported symptoms; pain is exacerbated in certain positions (TAO patients also complain that there is an exacerbation of pain due to the elevation of limbs). CT angiography performed in a position that provokes the symptoms can be helpful in establishing a diagnosis by documenting the significant restriction in flow. In more advanced stages of the disease, associated with constant compression of the subclavian artery and sometimes with compensative development of a subclavian aneurysm, the symptoms of critical hand ischemia may develop (Fig. 4) [40].

\section{Peripheral Embolism and Atherothrombotic Embolism}

The diagnosis is usually unproblematic if these complications develop in an older individual, e.g. with atrial fibrillation or massive atherosclerotic 


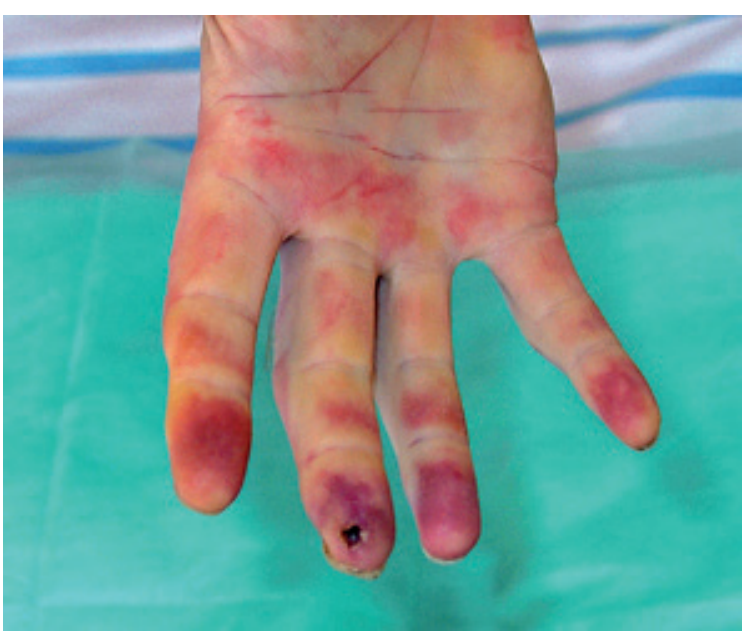

Fig. 4. A 45-year-old patient with critical ischemia of the third finger in the course of thoracic outlet syndrome (authors' own image)

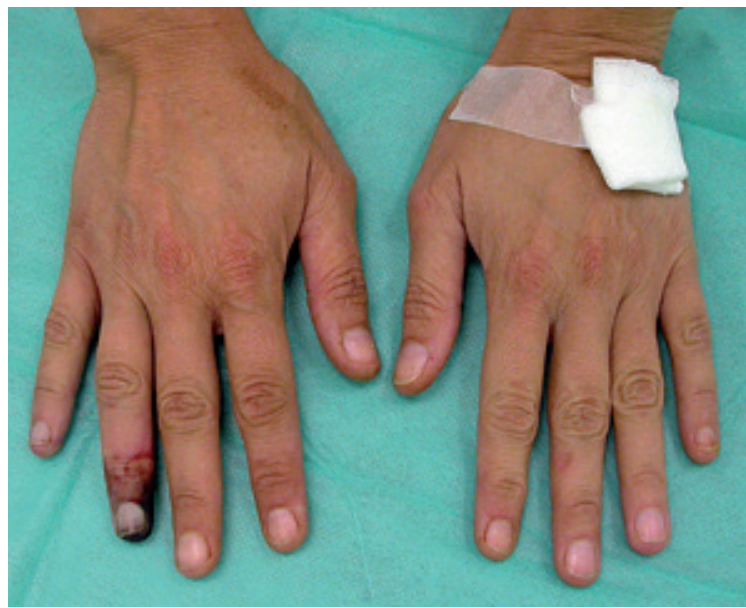

Fig. 5. A 25-year-old with patent foramen ovale and necrosis of the fourth finger of the right hand (authors' own image)

plaques. Problems with differentiating between these conditions and TAO can occur in the presence of a crossed (paradoxical) embolism, in young smokers and in individuals with a persistent foramen ovale, particularly co-existing with a flaccid inter-atrial septum (Fig. 5). However, the correct diagnosis is usually suggested by the rapid onset of the condition, the typical involvement of one site (e.g., one limb or finger) and the results of contrast echocardiography.

\section{Drug-Induced Vasculitides}

Drug-induced vasculitides caused by cannabis (cannabis arteritis) and cocaine are of growing importance, because they may be responsible for many cases of peripheral arterial insufficiency in adults under 50 years of age. In most cases of cannabis arteritis, claudication precedes the development of necrosis or gangrene of the toes, and often involves arteries below the knee (in ultrasonography or computed tomography, the lesions are indistinguishable from TAO). A history and toxicological profile are helpful, but making a correct diagnosis may be challenging [41].

\section{Infectious Endocarditis}

Infectious endocarditis (IE) is a septic condition that has a bacterial etiology in $>90 \%$ of the cases, and occasionally is of fungal origin. IE most commonly involves the aortic and mitral valves. Predisposing factors include congenital and acquired cardiac malformations, heart valve prostheses, immunosuppression, intracardiac electrode placement and intravenous drug abuse. Non-specific complaints (weakness, high-grade fever or persistent low-grade fever, increased perspiration, arthralgia and myalgia, loss of weight) predominate, along with symptoms associated with left heart involvement (murmurs associated with insufficiency of the involved valves, cardiac failure, embolic symptoms from CNS, celiac or limb arteries, including pain and peripheral vascular disorders, such as cutaneous and subungual splinter-like petechiae, painful, red Osler's nodes localized on the fingers and toes, or nonpainful hemorrhagic spots on the palms and soles - so-called Janeway lesions) [42]. In the case of an embolism caused by larger bacterial conglomerates, the signs of acute limb ischemia or peripheral microembolism can develop. The diagnosis is established on the basis of the clinical manifestations, the results of transthoracic or transesophageal echocardiography and blood culture. IE should be distinguished from the rare noninfectious Libman-Sacks endocarditis associated with systemic lupus erythematosus (SLE), in which papillomatous clots usually form on the mitral valve [42].

\section{Popliteal Entrapment Syndrome}

This anomaly develops predominantly in younger males (estimated prevalence $0.2-3.5 \%$ ) and involves the segment of popliteal artery located within the popliteal fossa. Intermittent claudication is the most frequent manifestation, but cases of acute ischemia associated with popliteal artery thrombosis have also been reported. The diagnosis is based on angiography and ultrasonography performed on the dorsal and plantar flexure of the foot [43]. 


\section{Takayasu's Disease}

This chronic large-vessel vasculitis usually affects younger women, who comprise $80-90 \%$ of all patients. Most commonly, the disease involves the aorta and the proximal segments of its branches, usually the carotid and subclavian arteries; however, cases of lower limb artery involvement within the aorto-iliac segment have also been reported. Initially, the symptoms are non-specific, subsequently progressing to symptoms associated with occlusion of the carotid and upper limb arteriesy. They can also encompass signs of CNS ischemia (focal disorders, vertigo, seizures), ophthalmic disturbances (blindness, glaucoma, cataract, numerous arteriovenous anastomoses of retinal vessels) and cardiac symptoms (injury to the aortic valve, arrhythmia, myocardial ischemia and heart failure) followed by arterial hypertension resulting from narrowing of the kidney artery, and complaints related to celiac artery involvement (paroxysmal stomach ache, diarrhea, bleeding from the alimentary tract). Frequently, individuals with more severe changes develop aneurysms that usually co-exist with multiple narrowed arterial lumina. The diagnosis can be supported by detecting the signs of activation of the inflammatory response and by imaging studies (ultrasonography, CT angiography and conventional angiography) revealing features that are absent in TAO patients: thickening of the vascular wall along with segmental smooth-walled narrowing, sometimes accompanied by dilatation of the vascular lumina [44].

\section{Primary Systemic Small- and Medium-Vessel Vasculitis}

Isolated cutaneous small-vessel vasculitis (previously referred to as leukocytoclastic vasculitis) is characterized by clinical manifestations that are different from those seen in TAO. Also, there are no signs of limb ischemia. At times, necrosis of a distal limb segments can be observed in the course of vasculitis associated with spontaneous mixed cryoglobulinemia (Fig. 6); however, the presence of cryoglobulins is detected in these cases, and the ankle-brachial index is normal. Aside from the presence of p-ANCA and c-ANCA type antibodies, the diagnosis of ANCA-positive inflammation (Wegener's granulomatosis, ChurgStrauss syndrome, and microscopic vasculitis) can be suggested by co-existing features of internal organ involvement, most frequently glomerulonephritis [45]. Cutaneous polyarteritis nodosa, a form of medium-sized vasculitis, is characterized

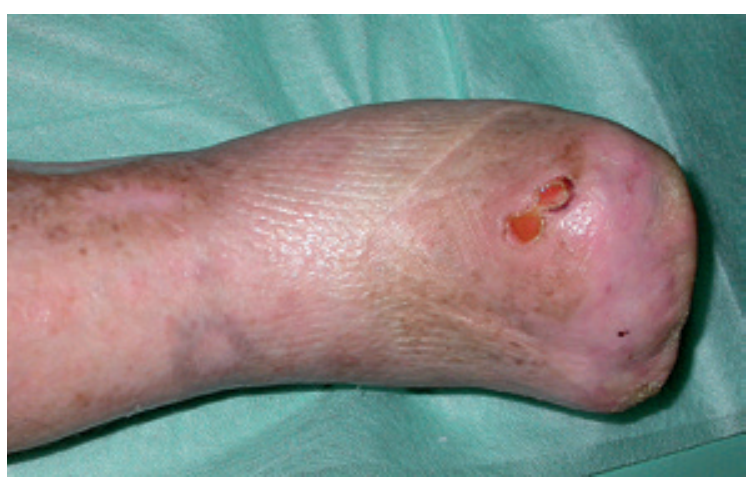

Fig. 6. A 50-year-old male patient with cryoglobulinemic vasculitis in the course of HBV infection (authors' own image)

by the presence of livedo reticularis and necrotic lesions, particularly involving the calves, sometimes with concurrent systemic symptoms (arthralgia, fever), but without occlusion of the below-knee arteries. The diagnosis is made on the basis of histological examination. Behçet's disease, another vasculitis affecting large-, medium- and small-sized vessels, can be distinguished from TAO on the basis of eye complications (uveitis, hypopyon), oral and urogenital aphtous ulcerations, as well as arthralgia; but superficial phlebitis can occur in both conditions [45].

\section{Secondary Systemic Vasculitis}

Secondary systemic vasculitis can involve a vessel of any size, but most commonly refers to small vessels; manifestations include erythema elevatum, nodes, urticarial efflorescence, livedo reticularis, or skin ulceration and necrosis. This condition can be associated with systemic connective tissue disorders (systemic sclerosis - Fig. 7), rheumatoid arthritis, SLE, Sjögren's syndrome, PM/DM), non-specific enteritis, malignant neoplasms (usually lymphoma), infections ( $\mathrm{HCV}, \mathrm{HBV}, \mathrm{HIV}$ ), and can occur as an adverse reaction to prescription drugs. Non-inflammatory Raynaud's microangiopathy is the predominant feature of systemic sclerosis (SSc), sometimes leading to chronic ischemia of fingers and the development of non-healing finger pad ulceration. Obliterating fibrosis of the tunica intima can be observed in histological specimens of the involved capillaries, and results from proliferation/edema of endothelial cells and subendothelial deposits of collagen. However, the typical histological features of necrotic vasculitis and the signs of critical limb ischemia (ulceration and dry necrotic lesions of palms and soles) can be observed in some SSc patients, usually in individuals with a limited 


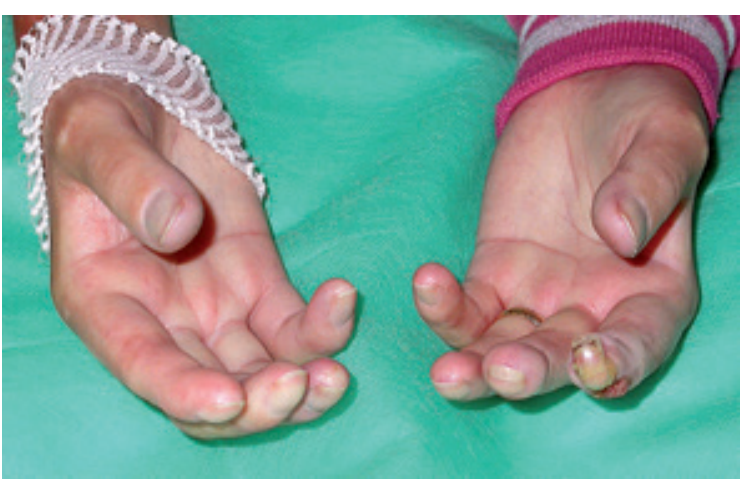

Fig. 7. Fingertip ulceration in a 35-year-old patient with diffuse systemic sclerosis. (authors' own image)

form of this disease (ISSc - limited systemic sclerosis), positive for anti-centromere antibodies, and/or with the symptoms of Sjögren's syndrome. In most cases, systemic vasculitis associated with mixed cryoglobulinemia develops secondarily to HCV infection [46].

\section{Peripheral Arterial Thrombosis}

Peripheral arterial thrombosis is an uncommon presentation of hereditary thrombophilias (antithrombin, protein $\mathrm{C}$ and S deficiency, factor V Leiden and prothrombin G20210A gene mutation); however, these may occur in acquired thrombophilias, particularly in the course of myeloproliferative neoplasms, i.e. essential thrombocytosis and polycythermia vera. The diagnosis is made on the basis of laboratory tests (blood count) and blood marrow biopsy [47].

\section{Hypothenar Hammer Syndrome}

Hypothenar hammer syndrome (HHS) is a rare form of ischemia involving fingers of the predominant hand, excluding the thumb. The disease is more prevalent in men than women, especially in individuals who are exposed to repeated blunt injuries of the hypothenar region. Most commonly, HHS is characterized by ischemia of the $4^{\text {th }}$ and/or $5^{\text {th }}$ finger, co-existing with such symptoms as pain, vasomotor disorders, paresthesia and cold intolerance. In advanced cases, symptoms can be accompanied by trophic lesions of the skin and finger necrosis. The diagnosis is verified on the basis of imaging studies, mostly angiography, confirming the presence of thrombosis or aneurysm located in the distal segment of the ulnar artery. Treatment and prevention of HHS include protection of the hand from mechanical injuries and quitting tobacco smoking. Additionally, anticoagulants and antiplatelet agents are administered, along with surgical revascularization and cervical sympathectomy. Thenar hammer syndrome (THS) is a similar, but even rarer, condition, characterized by thumb and/or index finger ischemia resulting from chronic post-traumatic thrombosis or thromboembolic complications associated with an aneurysm located in the distal segment of the radial artery [48].

\section{Antiphospholipid Syndrome}

This disease is caused by autoantibodies directed against protein-phospholipid complexes and manifests as recurrent episodes of venous and/or arterial thrombosis (Fig. 8) and pregnancy failures. It can have primary or secondary etiology, the latter most commonly associated with SLE. Livedo reticularis is the most typical dermal manifestation of APS; ulceration and necrotic lesions in various locations occur more rarely. Peripheral artery thrombosis can be accompanied by symptoms of acute or critical limb ischemia. The diagnosis is based on a history of vascular thrombosis and/or pregnancy failure and the presence of antiphospholipid antibodies detected at least twice at an interval of 12 weeks or more (moderate or high titers of lupus anticoagulant, and/or IgG or IgM class anti-cardiolipin antibodies, and/or antibodies against $\beta 2$-glycoprotein I). Antinuclear antibodies are detected in $45 \%$ of individuals with primary APS and thrombocytopenia is observed in $30 \%$ of the patients [49].

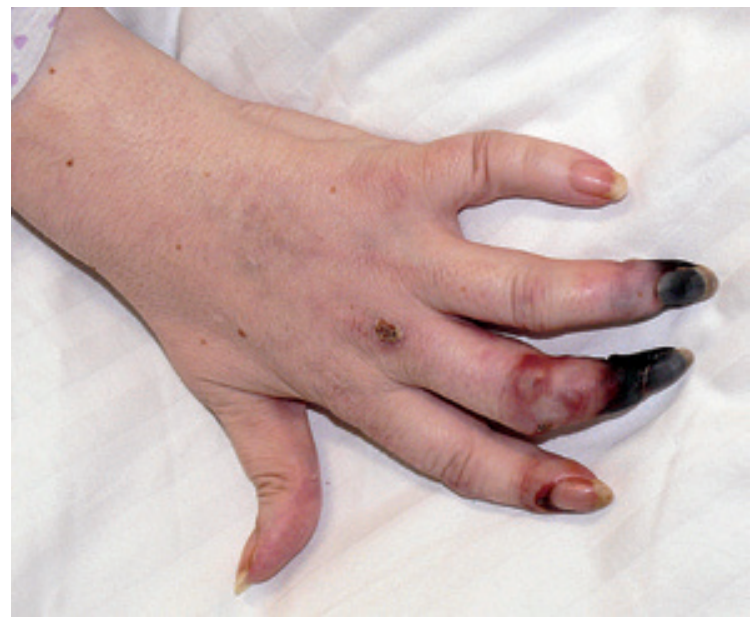

Fig. 8. Necrosis of the distal parts of the fingers in a 41-year-old female patient with antiposhoplipid syndrome, systemic lupus erythematosus and rheumatoid arthritis (authors' own image) 


\section{Persistent Sciatic Artery}

Persistent sciatic artery is a rare but clinically important developmental anomaly occurring in $0.1 \%$ of the population. It is observed when the sciatic artery does not undergo physiological regression during fetal development and persists as the predominant artery of the lower limb. Usually, this condition is associated with hypoplasia of the superficial femoral artery, which supplies only the upper part of the thigh. Persistent sciatic artery derives from one of the ramifications of the inferior gluteal artery and travels through the posterior aspect of the thigh along with the sciatic nerve, eventually passing into the popliteal artery. Its anatomical course means it is exposed to repeated injury, which frequently leads to thrombosis or aneurysm with resulting thromboembolic complications. Clinically, persistent sciatic artery can manifest as an aneurysm located in the gluteal region and acute, subacute or chronic limb ischemia. Arteriography is the gold standard for diagnosing this condition; among other anomalies, the examination reveals an unusually large internal iliac artery. Management of the complications resulting from the presence of a persistent sciatic artery usually involves the implantation of a femoropopliteal bypass [50].

\section{Infection with Anaerobic Clostridium sp. Bacilli}

Infection with anaerobic clostridium sp. bacilli (predominantly gas gangrene caused by C. perfringens) leads to the putrid decay of tissues, exacerbated by injury and ischemia. Gangrene develops only at anatomical sites that communicate directly with the external environment (and are thus accessible to the bacteria), such as the skin, particularly if exposed to crush injuries. The infected wound is surrounded by edema, redness and blisters filled with purulent exudate (so-called ichor) with a characteristic putrid smell. The proliferating bacteria release gas to the surrounding tissues, which can be detected by palpation and is visible in radiographs. In addition to the specific clinical manifestations and a history of recent injury, a proper diagnosis is supported by the results of an anaerobic culture of the wound content [51].

\section{Bristleworm Poisoning}

Bristleworms are venomous marine annelids. Contact with their venom most commonly occurs in connection with water sports, usually diving. A urticarial rash develops at the site pricked by bristleworm bristles and is accompanied by pain and burning paresthesia; inflammatory lesions and necrosis of the skin occur less often [52].

\section{Calcinosis Cutis}

Calcinosis cutis refers to the accumulation of calcium deposits in the skin. Dystrophic calcinosis, which usually develops in response to an injury, is the most frequent form of this condition. Other established causes include connective tissue disorders, hyperparathyroidism, tumors of the skin, chronic venous insufficiency and occupational exposure to calcium compounds. Skin lesions present as hard, whitish/yellowish papules, plaques or nodes that can undergo painful ulceration. Skin necrosis, including the fingers, can develop in more severe cases. The diagnosis is based on radiographic and histopathological examination, both of which reveal the presence of calcium deposits within subcutaneous tissue [53].

\section{Ergot Alkaloid Poisoning}

This disease is caused by a fungus - Claviceps purpurea - that parasitizes cereal grains. Its sclerotia, known as ergot, contain toxic alkaloids, mostly ergotamine and ergotoxine, which cause hallucinations and uterine and vascular smooth muscle spasms, leading to miscarriage and tissue necrosis. Ergotism, as the agent responsible for mass human poisoning, was first mentioned in the Middle Ages. The disease had two principal forms: convulsive (ergotismus convulsivus) and gangrenous (ergotismus gangraenosus). The latter form was also known as "Saint Anthony's fire" after monks of St. Anthony's Order who treated the victims of ergot poisoning during the medieval period. The symptoms of ergot alkaloid poisoning can be classified as convulsive (epileptic seizures, nausea, vomiting, headache), central (hallucinations, psychosis, hysteria and mania), and gangrenous (loss of peripheral pulse, loss of sensation, edema and dry necrosis of distal body parts, resulting from persistent arterial spasm). At present, overdosing with ergotamine-containing anti-migraine agents, or ingestion of its hallucinogenic synthetic derivatives (mostly LSD), are the most common causes of ergotism [54].

\section{Frostbites}

They are injuries of the skin resulting from exposure to low temperatures, usually as a consequence of total body hypothermia. Distal parts of the body, including the fingers and toes, are 


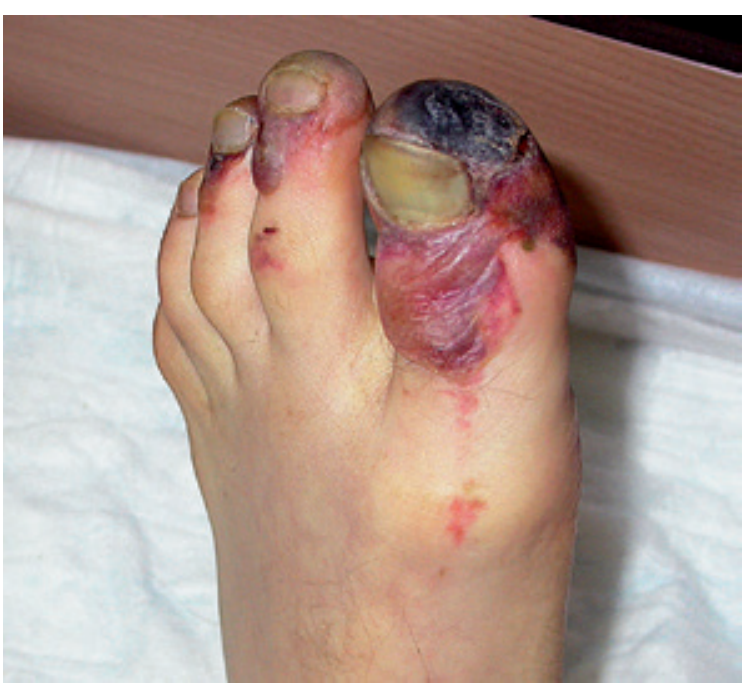

Fig. 9. Frostbitten toes in a 29 -year-old man with bipolar affective disorder (authors' own image)

particularly susceptible to frostbite. Depending on the severity, transient vasomotor disorders may be observed - pallor or livid coloration of the skin, edema, burnin, and pain (grade I), blisters filled with serous fluid (grade II) and superficial or deep skin necrosis (grade III, Fig. 9), which can lead to the spontaneous amputation of the frostbitten body part [55].

\section{Trench Foot/Immersion Foot Syndrome}

Trench foot/immersion foot syndrome is caused by prolonged exposure of the feet to wet, unsanitary and cold conditions (Fig. 10). Unlike frostbite, trench foot does not require freezing temperatures. The term "trench foot" comes from the trenches soldiers fought in during WWI; nowadays, the condition occurs most frequently in homeless people [56]. Erythema and numbness or tingling sensations occur initially, followed by tenderness and cyanosis due to vasoconstriction. Later painful foot swelling and hyperemia develops as a result of vascular paralysis. Advanced trench foot involves maceration of the skin, blisters, infected sores and gangrene, which can lead to a need for

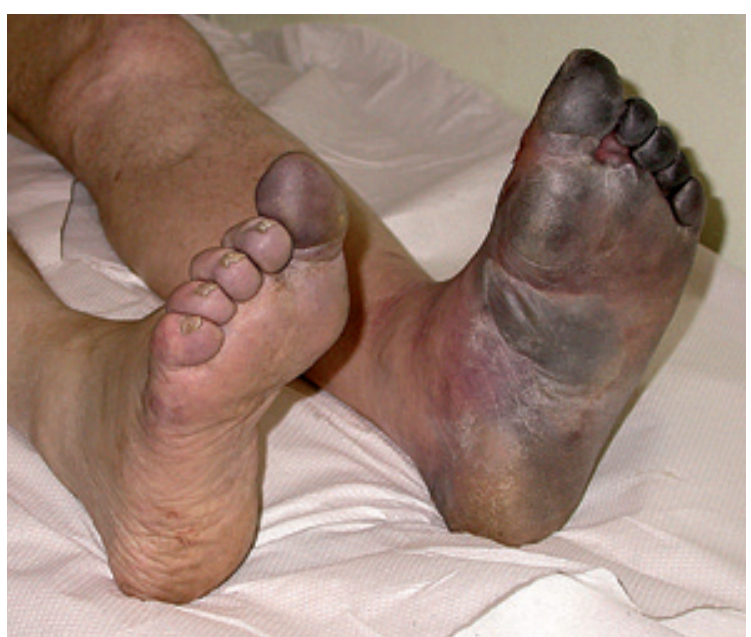

Fig. 10. A 65-year-old homeless man with trench foot. Both Doppler examination (ankle - brachial index) and ultrasonography excluded ischemia of the feet (authors' own image)

amputation. Dampness, tight shoes, immobility, as well as smoking and peripheral arterial disease contribute to tissue damage [56].

\section{Cystic Adventitial Disease}

Cystic adventitial disease (CAD) is a rare condition of unknown etiology, affecting peripheral arteries, commonly the popliteal artery, and responsible for abrupt-onset intermittent claudication. The lesion (cyst) can be visualized in computed tomography, magnetic resonance imaging or even ultrasonography, and can be distinguished from TAO on the basis of morphology, distribution and coexisting symptoms of TAO [57].

\section{Pseudoxantoma elasticum}

Pseudoxantoma elasticum is an uncommon hereditary disease, involving the skin, the cardiovascular system (arterial stenoses and intermittent claudication) and the gastrointestinal tract. The diagnosis is usually made in childhood or adolescence, and the presence of characteristic skin lesions as well as eye complications help in reaching the appropriate diagnosis [58].

\section{References}

[1] von Winiwarter F: Ueber eine eigenthumliche Form von Endarteriitis und Endophlebitis mit Gangran des Fusses. Arch Klin Chir 1879, 23, 202-226.

[2] Buerger L. Thrombo-angiitis obliterans: a study of the vascular lesions leading to presenile spontaneous gangrene. Am J Med Sci 1908, 136, 567-580.

[3] Olin JW: Thromboangiitis obliterans (Buerger's disease). N Engl J Med 2000, 343, 864-849.

[4] Adar R: Epidemiology of TAO - correction of an error. Atherosclerosis 2010, 211, 24.

[5] Mills JL, Porter JM: Buerger's disease (thromboangiitis obliterans). Ann Vasc Surg 1991, 5, 570-572.

[6] Kaniak J: Zapalenie tętnic o etologii nie znanej [Arterits of unknown ethiology]. In: Choroby naczyń. Ed. Rykowski H, PZWL, Warszawa 1981, 271. 
[7] Wysokiński WE, Kwiatkowska W, Sapian-Raczkowska B, Czarnacki M, Doskocz R, Kowal-Gierczak B: Sustained classic clinical spectrum of thromboangiitis obliterans (Buerger's disease). Angiology 2000, 51, 141-150.

[8] Tse TS, McBane RD, Stanson AW, Ballman KV, Mikhail MA, Cooper LT: Secular trends and long-term survival in thromboangiitis obliterans. J Am Coll Cardiol 2002, 39 (Suppl B), 265A.

[9] Sasaki S, Sakuma M, Yasuda K: Current status of thromboangiitis obliterans (Buerger's disease) in Japan. Int J Cardiol 2000, 75, Suppl 1, 175-181.

[10] Buerger L: Is thromboangiitis obliterans an infectious disease? Surg Gynecol Obstet 1914, 19, 582-588.

[11] Chen YW, Nagasawa T, Wara-Aswapati N, Ushida Y, Wang D, Takeuchi Y, Kobayashi H, Umeda M, Inoue Y, Iwai T, Ishikawa I, Izumi Y: Association between periodontitis and anti-cardiolipin antibodies in Buerger disease. J Clin Periodontol 2009, 36, 830-835.

[12] Marchetti C, Poggi P, Cornaglia AI, Farina A, Rizzo S: Morphologic characteristics of initial lymphatics of the healthy and diseased human gingiva. Anat Rec 1999, 255, 175-179.

[13] Iwai T: Periodontal bacteremia and various vascular diseases. J Periodontal Res 2009, 44, 689-694.

[14] Chen YW, Nagasawa T, Wara-Aswapati N, Ushida Y, Wang D, Takeuchi Y, Kobayashi H, Umeda M, Inoue Y, Iwai T, Ishikawa I, Izumi Y: Association between periodontitis and anti-cardiolipin antibodies in Buerger disease. J Clin Periodontol 2009, 36, 830-835.

[15] Iwai T, Inoue Y, Umeda M, Huang Y, Kurihara N, Koike M, Ishikawa I: Oral bacteria in the occluded arteries of patients with Buerger disease. J Vasc Surg 2005, 42, 107-115.

[16] Chen YW, Iwai T, Umeda M, Nagasawa T, Huang Y, Takeuchi Y, Ishikawa I: Elevated IgG titers to periodontal pathogens related to Buerger disease. Int J Cardiol 2007, 122, 79-81.

[17] Kubota T, Inoue Y, Iwai T, Kurihara N, Huang Y, Umeda M: Arterial thrombosis after intravenous infusion of oral bacterium in a rat model. Ann Vasc Surg 2008, 22, 412-416.

[18] Chen Z, Takahashi M, Naruse T, Nakajima T, Chen YW, Inoue Y, Ishikawa I, Iwai T, Kimura A: Synergistic contribution of CD14 and HLA loci in the susceptibility to Buerger disease. Hum Genet 2007, 122, 367-372.

[19] Masłowski L, McBane R, Alexewicz P, Wysokiński WE: Antiphospholipid antibodies in thromboangiitis obliterans. Vasc Med 2002, 7, 259-264.

[20] Huh JY, Yi DY, Hwang SG, Choi JJ, Kang MS: Characterization of antiphospholipid antibodies in chronic hepatitis B infection. Korean J Hematol 2011, 46, 36-40.

[21] Pereira de Godoy JM, Braile DM: Buerger's disease and anticardiolipin antibodies. Cardiovasc Med (Hagerstown) 2009, 10, 792-794.

[22] Undas A, Nowakowski T, Cieśla-Dul M, Sadowski J: Abnormal plasma fibrin clot characteristics are associated with worse clinical outcome in patients with peripheral arterial disease and thromboangiitis obliterans. Atherosclerosis 2011, 215, 481-486.

[23] Zheng P, Chen SJ, Shao HZ: Studies on hypercoagulation state in thromboangiitis obliterans. Chin Med J (Engl) 1989, 102, 67-71.

[24] Avcu F, Akar E, Demirkilic U, Yilmaz E, Akar N, Yalcin A: The role of prothrombotic mutations in patients with Buerger's disease. Thromb Res 2000, 100, 143-147.

[25] Brodmann M, Renner W, Stark G, Winkler M, Pabst E, Hofmann C, Pilger E: Prothrombotic risk factors in patients with thrombangitis obliterans. Thromb Res 2000, 99, 483-486.

[26] Dellalibera-Joviliano R, Joviliano EE, Evora PR: Determination of kininogens levels and kallikrein/kininase II activities in patients with thromboangiitis obliterans. Scand J Immunol 2010, 72, 128-133.

[27] Kaniak J, Kurzawska M, Włodarczyk J, Prastowski W, Fal W, Kotschy M: Kininy osoczowe u chorych z zakrzepowo-zarostowym zapaleniem naczyń krwionośnych (w chorobie Buergera). Pol Arch Med Wewn 1972, 48, 113-119.

[28] Idei N, Nishioka K, Soga J, Hidaka T, Hata T, Fujii Y, Fujimura N, Maruhashi T, Mikami S, Teragawa H, Kihara Y, Noma K, Chayama K, Higashi Y: Vascular function and circulating progenitor cells in thromboangitis obliterans (Buerger's disease) and atherosclerosis obliterans. Hypertension 2011, 57, 70-78.

[29] Azizi M, Boutouyrie P, Bura-Rivière A, Peyrard S, Laurent S, Fiessinger JN: Thromboangiitis obliterans and endothelial function. Eur J Clin Invest 2010, 40, 518-526.

[30] Halacheva K, Gulubova MV, Manolova I, Petkov D: Expression of ICAM-1, VCAM-1, E-selectin and TNF-alpha on the endothelium of femoral and iliac arteries in thromboangiitis obliterans. Acta Histochem 2002, 104, $177-184$.

[31] Lee T, Seo JW, Sumpio BE, Kim SJ: Immunobiologic analysis of arterial tissue in Buerger's disease. Eur J Vasc Endovasc Surg 2003, 25, 451-457.

[32] Czarnacki M, Gacka M, Adamiec R: Rola endoteliny-1 w patogenezie choroby Buergera (doniesienie wstępne). Przegl Lek 2004, 61, 1346-1350.

[33] Slavov ES, Stanilova SA, Petkov DP, Dobreva ZG: Cytokine production in thromboangiitis obliterans patients: new evidence for an immune-mediated inflammatory disorder. Clin Exp Rheumatol 2005, 23, 219-226.

[34] Małecki R, Zdrojowy K, Adamiec R: Thromboangiitis obliterans in the $21^{\text {st }}$ century - a new face of disease. Atherosclerosis 2009, 206, 328-334.

[35] Ates A, Yekeler I, Ceviz M, Erkut B, Pac M, Basoglu A, Kocak H: One of the most frequent vascular diseases in northeastern of Turkey: Thromboangiitis obliterans or Buerger's disease (experience with 344 cases). Int J Cardiol 2006, 111, 147-153.

[36] Shionoya S: What is Buerger's disease? World J Surg 1983, 7, 544-551.

[37] Papa MZ, Rabi I, Adar R: A point scoring system for the clinical diagnosis of Buerger's disease. Eur J Vasc Endovasc Surg 1996, 11, 335-339. 
[38] Szuba A, Wysokiński W, Czarnacki M, Kurzawska-Mielecka M: Coexistence of Buerger's disease with atherosclerosis obliterans. In: $9^{\text {th }}$ International Symposium on Atherosclerosis 1991 (Abstract; item 178).

[39] Fujii Y, Soga J, Nakamura S, Hidaka T, Hata T, Idei N: Classification of corkscrew collaterals in thromboangiitis obliterans (Buerger's disease): relationship between corkscrew type and prevalence of ischemic ulcers. Circ J 2010, $74,1684-1688$.

[40] Demondion X, Herbinet P, Van Sint Jan S, Boutry N, Chantelot C, Cotten A: Imaging assessment of thoracic outlet syndrome. Radiographics 2006, 26, 1735-1750.

[41] Noël B, Ruf I, Panizzon RG: Cannabis arteritis. J Am Acad Dermatol 2008, 58, 65-67.

[42] Servy A, Valeyrie-Allanore L, Alla F, Lechiche C, Nazeyrollas P, Chidiac C: Prognostic value of skin manifestations of infective endocarditis. JAMA Dermatol 2014, 150, 494-500.

[43] Radonić V, Koplić S, Giunio L, Bozić I, Masković J, Buća A: Popliteal artery entrapment syndrome: diagnosis and management, with report of three cases. Tex Heart Inst J 2000, 27, 3-13.

[44] Mason JC: Takayasu arteritis - advances in diagnosis and management. Nat Rev Rheumatol 2010, 6, 406-415.

[45] Waller R, Ahmed A, Patel I, Luqmani R: Update on the classification of vasculitis. Best Pract Res Clin Rheumatol 2013, 27, 3-17.

[46] Retamozo S, Brito-Zerón P, Bosch X, Stone JH, Ramos-Casals M: Cryoglobulinemic disease. Oncology (Williston Park) 2013, 27, 1098-1105.

[47] Gacka MA, Adamiec R, Kowal P: Trophic Lesions of the Lower Limbs As Exponents of Vascular Complications in Essential Thrombocythemia. Adv Clin Exp Med 2011, 20, 455-460.

[48] Kluz J, Małecki R, Adamiec R: Hypothenar hammer syndrome complicated by critical finger ischemia in a fight sports instructor - a case report. Acta Angiol 2006, 12, 180-186.

[49] Cohen D, Berger SP, Steup-Beekman GM, Bloemenkamp KWM, Bajema IM: Diagnosis and management of the antiphospholipid syndrome. BMJ 2010, 340, 2541.

[50] Abdallah M, Gashti M, McEvenue GM: Persistent sciatic artery aneurysm presenting with limb-threatening ischemia: a case report and review. Vasc Dis Manag 2010, 7, 82-85.

[51] Stevens DL, Aldape MJ, Bryant AE: Life-threatening clostridial infections. Anaerobe 2012, 18, 254-259.

[52] Schwartz S, Meinking T: Venomous marine animals of Florida: morphology, behavior, health hazards. J Fla Med Assoc 1997, 84, 433-440.

[53] Li Q, Uitto J: Mineralization/anti-mineralization networks in the skin and vascular connective tissues. Am J Pathol 2013, 183, 10-18.

[54] Zavaleta EG, Fernandez BB, Grove MK, Kaye MD: St. Anthony's fire (ergotamine induced leg ischemia) - a case report and review of the literature. Angiology 2001, 52, 349-356.

[55] Handford C, Buxton P, Russell K, Imray CE, McIntosh SE, Freer L, Cochran A, Imray CH: Frostbite: a practical approach to hospital management. Extrem Physiol Med 2014, 3, 7.

[56] Imray CHE, Richards P, Greeves J, Castellani JW: Nonfreezeing cold-induced injuries. J R Army Med 2011, 157, 79-84.

[57] Desy NM, Spinner RJ: The etiology and management of cystic adventitial disease. J Vasc Surg 2014, 60, $235-245$.

[58] Marconi B, Bobyr I, Campanati A, Molinelli E, Consales V, Brisigotti V: Pseudoxanthoma elasticum and skin: Clinical manifestations, histopathology, pathomechanism, perspectives of treatment. Intractable Rare Dis Res $2015,4,113-122$.

\section{Address for correspondence:}

Joanna Przeździecka-Dołyk

Wańkowicza 50/6

54-622 Wrocław

Poland

E-mail: arie_l@wp.pl

Conflict of interest: None declared

Received: 17.08.2014

Revised: 28.10.2014

Accepted: 11.12.2014 